\title{
Girişimsel radyoloji bölümünde lokal anestezi ile işlem yapılan hastaların ağrı ve anksiyete (endişe) durumlarının belirlenmesi
}

\author{
Determining pain and anxiety situations of patients who underwent interventional \\ radiologic procedure with local anesthesia in interventional radiology department
}

\author{
Bediye Öztaş ${ }^{1} \quad$ Emine İyigün ${ }^{2} \mathbb{D}$ \\ ${ }^{1}$ Yüksek İhtisas Üniversitesi, Sağlık Bilimleri Fakültesi Hemşirelik Bölümü, Ankara, Türkiye \\ ${ }^{2}$ Gülhane Sağlık Bilimleri Üniversitesi, Hemşirelik Bölümü, Ankara, Türkiye
}

\section{Öz}

Amaç: Bu çalışmanın amacı; çok çeşitli hasta profiline sahip olan girişimsel radyoloji bölümünde lokal anestezi ile işlem yapılan hastaların işlem öncesi ve sonrasında ağıı ve anksiyete durumlarının belirlenmesidir.

Gereç ve Yöntem: Araştırma; yarı deneysel olarak planlanmıştır. Araştırmada örneklem seçimine gidilmemiş olup belirtilen tarihler arasında araştırmaya dahil olma kriterlerine uyan ve araştırmaya katılmayı kabul eden 100 hasta araştırmanın örneklemini oluşturmuştur. Hastaların ağı ve anksiyete durumlarını belirlemek için birden ona kadar numaralanmış Visüel Analog Skala (VAS) kullanılmıştır. Verilerin değerlendirilmesinde frekans dağılımları, Kruskall Wallis, Mann Whitney U, Pearson Korelasyon testleri kullanılmıştır.

Bulgular: İşlem öncesinde hastaların; \%78'si ağrı beklentisini, \%71'i ise anksiyete seviyesini VAS'a göre 4 ve üzeri puan vererek ifade etmişlerdir. İşlem sonrasında hastaların; \%37'si ağrısını, \%38'i anksiyetesini VAS'a göre 4 ve üzeri puan vererek ifade etmişlerdir. Girişimsel radyoloji bölümünde nonvasküler işlem yapılan hastaların işlem öncesi ve işlem sonrası anksiyete puanları vasküler işlem yapılan hastalara göre istatistiksel olarak daha yüksek bulunmuştur $(p<0,001)$.

Sonuç: Hastaların ağrı ve anksiyete durumlarının belirlenmesi hastaların işlem sırasında uyumunu arttıracak, hemodinamik belirteçlerin normalden sapmasını en aza indirecek, istenmeyen durumların ortaya çıkışını azaltacak ve hasta memnuniyetini arttıracaktır.

Anahtar Sözcükler: Girişimsel radyoloji, ağrı, anksiyete.

\begin{abstract}
Aim: The aim of the present study is to determine the pain and anxiety levels in patients before and after undergoing a procedure under local anesthesia in the department of interventional radiology, which has a variable patient profile.

Materials and Methods: The study was designed as a semi-experimental research involving no particular sample profile. Consequently, the study sample comprised 100 patients who met the study inclusion criteria between the specified dates, and who agreed to participate in the study. The 10-point Visual Analogue Scale (VAS) was used to evaluate pain and anxiety levels, and the data analysis assessed frequency distribution through Kruskall Wallis and Mann-Whitney $U$ tests and a Pearson's correlation coefficient.
\end{abstract}

Results: Prior to the procedure, 78 percent of the patients reported pain expectancy and 71 percent reported an anxiety level of 4 points or over according to VAS. After the procedure, 37 percent of the patients reported pain levels and 38 percent reported anxiety levels of 4 points or over according to VAS. Patients undergoing nonvascular procedures in the department of interventional radiology reported significantly higher anxiety scores before and after the procedure than patients undergoing vascular procedures $(p<0.001)$.

\footnotetext{
Yazışma Adresi: Bediye Öztaş

Yüksek İhtisas Üniversitesi, Sağlık Bilimleri Fakültesi Hemşirelik

Bölümü, Ankara, Türkiye

E-mail: oztasbediye2@gmail.com

Makalenin Geliş Tarihi: 18.05.2018 Kabul Tarihi: 01.10.2018
} 
Conclusions: Determining the pain and anxiety levels in patients will increase the compliance of patients during procedures, minimize deviations from the norm in hemodynamic parameters, reduce the occurrence of undesired events and increase patient satisfaction.

Keywords: Interventional radiology, pain, anxiety.

\section{Giriş}

Girişimsel radyoloji birimi hastalıkların tanı ve tedavisinde geniş yer tutan, vasküler ve nonvasküler işlemlerin yapıldığı bir birimdir. Girişimsel radyolojik işlemler radyasyon bilimi teknolojisi değiştikçe ve geliştikçe daha invaziv, karmaşık, tercih edilir ve kolay ulaşılabilir olmaya başlamıştır (1). Girişimsel radyoloji biriminde hastalara işlemler planlı bir zaman diliminde yapılabilirken acil olarak da yapılabilmektedir. Bazı işlemlerde genel anestezi gerekirken çoğunlukla işlemler lokal anestezi altında gerçekleştirilmektedir (2). Hastalar hızlı bir şekilde değerlendirildikten ve kısa bir karar verme sürecinden sonra tanı ve tedavi amacıyla girişimsel radyoloji biriminde bulunabilmektedirler (3). Hastalar hastane ortamının özellikle de radyoloji bölümünün farklılığı, yaşanan iletişim problemleri, bekleme süresi, bilinmeyen aletlerin kullanılması ve bilgi eksikliği gibi nedenlerden dolayı anksiyete yaşayabilmektedirler (4).

Girişimsel radyoloji bölümünde, işlemlerin çoğunluğunun lokal anestezi ile sedasyon uygulanmadan yapılmasının avantajlarının yanı sıra hastalar ciddi boyutta ağrı ve anksiyete yaşayabilmektedirler (5-7). Hastaların anksiyeteleri ve anksiyete ile baş etme yetenekleri; solunum sayı ve niteliğini, kalp atım hızını, kan basıncını, miyokardiyal oksijen tüketimini ve plazma epinefrinnorepinefrin düzeyini etkileyerek hastanın fizyolojik yanıtını değiştirebilmektedir. Hastada gelişen fizyolojik ve psikolojik değişiklikler; işlemin süresinin uzamasına ve eğer sedasyon uygulanacaksa verilecek ilaç miktarının artmasına neden olabilmektedir. Benzer şekilde hastanın ağrı ve anksiyetesi sağlık ekibi ile uyumunu olumsuz yönde etkileyebilmekte ve işlemin teknik olarak zor geçmesine neden olabilmektedir (4). Girişimsel radyoloji biriminin tıp alanına katkıları bu birimde hastalara sunulan hizmetin daha etkili, kaliteli, güvenli ve konforlu sunulması gerekliliğini doğurmuştur. Buna paralel olarak; sağlık bakımı sunumunun önemli temsilcilerinden olan hemşirelerin girişimsel radyoloji bölümünde görüntüleme yöntemleri kullanılarak bilinçli hastalara yapılan invaziv işlemlerde, hastaların ağrı ve anksiyete durumlarını değerlendirmeleri öncelik kazanmaktadır.
Ülkemizde girişimsel radyoloji üniteleri sağlık hizmetlerinde giderek daha fazla yer tutmaya başlamıştır. Girişimsel radyolojik işlemlerin genel olarak sedasyon uygulanmadan, lokal anestezi ile yapılması ve literatürde hastaların girişimsel radyolojik işlemlerde yaşadıkları ağrı ve anksiyeteyi değerlendiren çalışmaya çok az rastlanması nedeniyle bu çalışmaya ihtiyaç duyulmuştur $(8,9)$. Bu çalışmanın amacı; çok çeşitli hasta profiline sahip olan girişimsel radyoloji bölümünde lokal anestezi ile işlem yapılan hastaların işlem öncesinde ve sonrasında ağrı ve anksiyete durumlarının belirlenmesidir.

\section{Gereç ve Yöntem}

Araştırma; kesitsel ve tanımlayıcı olarak planlanmıştır. Araştırmanın verileri; Ekim 2013Aralık 2014 tarihleri arasında girişimsel radyoloji biriminde lokal anestezi ile işlem yapılan hastalarla yüz yüze görüşülerek toplanmıştır. Araştırmada örneklem seçimine gidilmemiş olup belirtilen tarihler arasında araştırmaya dahil olma kriterlerine uyan ve araştırmaya katılmayı kabul eden 100 hasta, araştırmanın örneklemini oluşturmuştur. Araştırmaya dahil olma kriterleri; girişimsel radyoloji bölümünde lokal anestezi ile işlem yapılan hasta olmak, 18 yaş üstü olmak, Türkçe bilmek ve araştırmaya katılmayı kabul etmek olarak belirlenmiştir. Dışlanma kriterleri ise; mental yetersizliği olan hastalar, işlemden 4 saat öncesine kadar herhangi bir analjezik, sedatif ve anksiyolitik almış olan hastalar, lokal anestetik madde alerjisi olan hastalar, yoğun bakım ekipmanı ile işleme gelen hastalar, birden fazla işlem yapılan (vasküler+nonvasküler ya da diagnostik+terapötik) hastalar, antidepresan tedavisi alan hastalar olarak belirlenmiştir. Veri toplama formu; doğum tarihi, eğitim durumu, cinsiyet, boy, kilo, beden-kitle indeksi (BKI), hastanın fiziki bağımlılık durumu, yapılacak işlemle ilgili sağlık personeli tarafından bilgilendirilmeden önce bilgisi, daha önce işlemle ilgili deneyimi, yapılacak işlemin adı, işlem süresi, işlemde kullanılan iğnenin kalınlığı bilgilerinden oluşan bir form ile işlem öncesi ve işlem sonrası hastanın birden ona kadar numaralanmış Visüel Analog Skala'ya (VAS) göre ağrı ve anksiyete (endişe) düzeylerinin sorulduğu bir formdan 
oluşmuştur. İşlem öncesinde hastalar operasyon masasına alındığında, işlem başlamadan ağrı beklentisi ve anksiyete durumları sorgulanmıştır. Hastalara yüzeyel işlemlerde $90 \mathrm{mg}$ prilokain hidroklorür (Citanest; AstraZeneca, İstanbul, Türkiye), derin işlemlerde $300 \mathrm{mg}$ prilokain hidroklorür lokal anestezi sağlamak için kullanılmıştır. İşlem sonrasında ise işlemin tamamlanmasını takiben iki dakika içerisinde hastaların ağrı ve anksiyete durumları sorgulanmıştır. Tüm analizler için SPSS (IBM Corp. Released 2013. IBM SPSS Statistics for Windows, Version 21.0. Armonk, NY: IBM Corp.) programı kullanılmıştır. Verilerin değerlendirilmesinde frekans dağılımları, Kruskall Wallis, Mann Whitney $\mathrm{U}$, Pearson Korelasyon testleri kullanılmıştır. Araştırmanın yapılabilmesi için girişimsel radyoloji biriminden yazılı izin alındıktan sonra etik kurul izni alınmıştır. Veri toplama aşamasında hastaların yazılı ve sözlü onamları alınmıştır.

\section{Bulgular}

$\mathrm{Bu}$ çalışmanın örneklemini girişimsel radyoloji bölümünde işlem yapılan 100 hasta oluşturmuştur. Tablo-1'de görüldüğü gibi hastaların çoğunluğunu erkekler (\%62) oluşturmuştur. Hastaların \%52'si normal sınırlarda beden kitle indeksine sahiptir. Hastaların \%94'ü fiziki olarak bağımsız durumdadır. Girişimsel radyoloji bölümünde yapılan ve araştırmada değerlendirilen işlemlerin listesi Tablo-2'de verilmiştir. Hastaların işlem öncesi ve sonrasında VAS a göre belirttikleri ağrı ve anksiyete puan ortalamaları Tablo-3'de verilmiştir. İşlem öncesinde hastaların; \%78'si ağrı beklentisini, \%71'i ise anksiyete seviyesini VAS'a göre 4 ve üzeri puan vererek ifade etmişlerdir. İşlem sonrasında ise hastaların \%37'si ağrısını, $\% 38$ 'i anksiyetesini VAS'a göre 4 ve üzeri puan vererek ifade etmişlerdir.

Araştırmanın bağımlı ve bağımsız değişkenleri arasındaki istatistiksel değerlendirme test ve sonuçları Tablo-4'te verilmiştir. Hastaların BKI ile işlem öncesi anksiyete puanları arasında pozitif düşük düzeyde bir korelasyon vardır $(p=0,007$ $r=0,269$ ). Hastaların BKi'si arttıkça yaşadıkları anksiyete seviyesi artmaktadır. Nonvasküler işlem yapılan hastaların beden kitle indeksi ile işlem öncesi yaşadıkları anksiyete puanları arasında pozitif orta düzeyde bir korelasyon vardır ( $p<0,001$, $r=0,485$ ). Araştırmaya katılan kadın hastaların işlem öncesi ağrı beklentileri erkek hastalara göre istatistiksel olarak daha yüksek bulunmuştur $(p=0,003)$.
Girişimsel radyoloji bölümünde işlem yapılan kadın hastalar işlem öncesi ve sonrasında erkek hastalara göre daha yüksek seviyede anksiyete yaşamaktadırlar ve bu fark istatistiksel olarak anlamlıdır $(p<0,001, p=0,001)$. Girişimsel radyoloji bölümünde daha önce benzer işlemler geçiren deneyimli hastaların işlem öncesi ve işlem sonrası anksiyete puan ortalamaları deneyimi olmayan hastalara göre istatistiksel olarak anlamlı derecede daha düşük bulunmuştur ( $p=0,039, p=0,044)$.

Girişimsel radyoloji bölümünde nonvasküler işlem yapılan hastaların işlem öncesi ve işlem sonrası anksiyete puanları vasküler işlem yapılan hastalara göre istatistiksel olarak daha yüksek bulunmuştur $(p<0,001)$. İşlem öncesi hastaların bekledikleri ağrı puanları ile işlem sonrası ağrı puanlarına bakıldığında ise nonvasküler işlem yapılan hastaların vasküler işlem yapılan hastalara göre puanları istatistiksel olarak anlamlı derecede yüksek bulunmuştur $(p<0,001)$.

Vasküler işlem yapılan hastaların işlem sonrası ağrı ve anksiyete puanları ile işlem süresi arasında pozitif ve orta düzeyde bir korelasyon vardır $(p=0,002, r=0,437 ; p=0,023, r=0,325)$.

İşlem öncesi anksiyete düzeyi yüksek olan hastaların işlem sonrasında da anksiyete düzeyi daha yüksek bulunmuştur. Hastaların işlem öncesi anksiyete puanları ile işlem sonrası anksiyete puanları arasında anlamlı ve pozitif yönde orta düzeyde ilişki vardır ( $p<0,001, r=0,621)$.

İşlem öncesinde anksiyete düzeyi yüksek olan hastaların; işlemden bekledikleri ağrı düzeyi ve işlem sonrasında belirttikleri ağrı seviyesi daha yüksektir. Hastaların işlem öncesi anksiyete puanları ile işlem öncesi ve sonrası ağrı puanları arasında anlamlı ve pozitif yönde orta düzeyde ilişki vardır $(p<0,001, r=0,457 ; p<0,001, r=0,352)$.

İşlemden önce ağrı beklentisi yüksek olan hastaların işlem sonrasında da yüksek düzeyde ağrı deneyimledikleri görülmüştür. Hastaların işlem öncesi işlemden bekledikleri ağrı puanları ile işlem sonrası ağrı puanları arasında anlamlı ve pozitif yönde orta düzeyde ilişki vardır $(p=0,001, r=0,315)$ Aynı şekilde işlem öncesi ağrı beklentisi yüksek olan hastaların işlem sonrası anksiyete puanları da yüksektir ve bu ilişki pozitif yönde orta düzeydedir $(p=0,002, \quad r=0,301)$. İşlem sonrası anksiyete puanları yüksek olan hastaların, işlem sonrası ağrı puanları da yüksektir ve bu ilişki pozitif yönde orta düzeydedir $(p<0,001, r=0,385)$.

Hastaların yaşları, iğne kalınlığı, eğitim durumu, fiziksel bağımlıık durumu, işlemle ilgili bilgili olma durumu; işlem öncesi ağrı beklentisi, işlem öncesi anksiyete durumu, işlem sonrası ağrı ve işlem sonrası anksiyete durumlarını etkilememiştir. 
Tablo-1: Sosyodemografik özellikler.

\begin{tabular}{|c|c|}
\hline & $\%$ \\
\hline Yaş & Ort. $=50,68$ \\
\hline \multicolumn{2}{|l|}{ Cinsiyet } \\
\hline Erkek & 62 \\
\hline Kadın & 38 \\
\hline \multicolumn{2}{|l|}{ Eğitim durumu } \\
\hline En az ilkokul mezunu olan & 33 \\
\hline Ortaokul mezunu olan & 22 \\
\hline Lise mezunu olan & 23 \\
\hline Lisans-lisansüstümezunu olan & 22 \\
\hline \multicolumn{2}{|l|}{ BKi } \\
\hline $18,5 \mathrm{~kg} / \mathrm{m}^{2} \mathrm{nin}$ altı & 4 \\
\hline $18,6-24,9 \mathrm{~kg} / \mathrm{m}^{2}$ arası & 52 \\
\hline $25 \mathrm{~kg} / \mathrm{m}^{2}$ üstü & 46 \\
\hline \multicolumn{2}{|l|}{ Fiziki bağımlılık durumu } \\
\hline Tam bağımlı & - \\
\hline Yarı bağımlı & 6 \\
\hline Bağımsız & 94 \\
\hline \multicolumn{2}{|c|}{ Yapılacak işlemle ilgili bilgi durumu } \\
\hline \multicolumn{2}{|l|}{ Var } \\
\hline \multirow[t]{2}{*}{ Yok } & 50 \\
\hline & 50 \\
\hline \multicolumn{2}{|l|}{ Daha önce işlemle ilgili deneyimi } \\
\hline \multicolumn{2}{|l|}{ Var } \\
\hline \multirow[t]{2}{*}{ Yok } & 48 \\
\hline & 52 \\
\hline \multicolumn{2}{|l|}{ Yapılan işlem } \\
\hline Vasküler işlem & 50 \\
\hline Nonvasküler işlem & 50 \\
\hline İşlem süresi & Ort.=39,54 dk. \\
\hline Toplam & 100 \\
\hline
\end{tabular}

$\mathrm{n}$ : örneklem sayısı ort.:ortalama dk.: dakika

Tablo-2: Girişimsel radyoloji bölümünde yapılan ve araştırmada değerlendirilen işlemler.

\begin{tabular}{lc}
\hline İşlem Adı & Sayı (n) \\
\hline Biyopsi & 42 \\
Angiografi & 26 \\
Vasküler stent yerleştirme & 9 \\
Radyoembolizasyon & 8 \\
Kemoembolizasyon & 3 \\
Drenaj kateteri yerleştime & 5 \\
Venografi & 2 \\
Kist hidatik tedavisi & 2 \\
Nefrostomi & 1 \\
Embolizasyon & 2 \\
\hline
\end{tabular}


Tablo-3: Girişimsel radyoloji bölümünde işlem yapılan hastaların ağıı ve anksiyete puan ortalamaları*.

\begin{tabular}{llll}
\hline İşlem Zamanı & Genel & Vasküler işlemler & Nonvasküler işlemler \\
\hline İşlem öncesi anksiyete & $5,69 \pm 3,07$ & $4,80 \pm 2,98$ & $6,58 \pm 2,92$ \\
İşlem öncesi ağrı beklentisi & $5,42 \pm, .22$ & $5,12 \pm 2,18$ & $5,72 \pm 2,24$ \\
İşlem sonrası anksiyete & $2,88 \pm 2,53$ & $2,16 \pm 2$ & $3,60 \pm 2,81$ \\
İşlem sonrası ağrı & $3,45 \pm 2,6$ & $2,96 \pm 2,32$ & $3,94 \pm 2,79$ \\
\hline
\end{tabular}

*Değerlendirmeler 1 ile 10 arasında numaralandırılmış skala ile yapıımıştır.

Tablo-4: Bağımsız değişkenlerle bağımlı değişkenlerin istatiksel olarak değerlendirilmesi.

\begin{tabular}{|c|c|c|c|c|}
\hline Özellik & $\begin{array}{l}\text { İşlem öncesi } \\
\text { anksiyete puanı }\end{array}$ & $\begin{array}{l}\text { İşlem öncesi ağrı } \\
\text { puanı }\end{array}$ & $\begin{array}{l}\text { İşlem sonrası } \\
\text { anksiyete puanı }\end{array}$ & $\begin{array}{l}\text { İşlem sonrası } \\
\text { ağrı puanı }\end{array}$ \\
\hline \multirow{2}{*}{ Yaş } & ${ }^{*} p=0,472$ & ${ }^{*} p=0,393$ & ${ }^{*} p=0,539$ & ${ }^{*} p=0,639$ \\
\hline & $r=-0,073$ & $r=-0,086$ & $r=-0,055$ & $r=-0,048$ \\
\hline Cinsiyet & ${ }^{* *} p<0,001$ & ${ }^{* *} p=0,003$ & ${ }^{* *} p=0,001$ & ${ }^{* *} p=0,060$ \\
\hline Eğitim durumu & ${ }^{\star \star *} p=0,267$ & ${ }^{* * *} p=0,195$ & ${ }^{* * *} p=0,468$ & ${ }^{* * *} p=0,776$ \\
\hline \multirow{2}{*}{ BKI } & ${ }^{*} p=0,007$ & ${ }^{*} p=0,186$ & ${ }^{*} p=0,069$ & ${ }^{*} p=0,559$ \\
\hline & $r=0,269$ & $r=0,133$ & $r=0,183$ & $r=0,059$ \\
\hline $\begin{array}{l}\text { Fiziksel bağımlılık } \\
\text { durumu }\end{array}$ & ${ }^{\star * *} p=0,267$ & ${ }^{* * *} p=0,066$ & ${ }^{* * *} p=0,586$ & ${ }^{* * *} p=0,393$ \\
\hline $\begin{array}{l}\text { Yapılacak işlemle ilgili } \\
\text { bilgi durumu }\end{array}$ & ${ }^{* *} p=0,098$ & ${ }^{* *} p=0,521$ & ${ }^{* *} p=0,213$ & ${ }^{* *} p=0,373$ \\
\hline $\begin{array}{l}\text { Daha önce işlemle } \\
\text { ilgili deneyimi }\end{array}$ & ${ }^{* *} p=0,039$ & ${ }^{* *} p=0,219$ & ${ }^{* *} p=0,044$ & ${ }^{* *} p=0,997$ \\
\hline Yapılan işlem & ${ }^{* *} p=0,004$ & ${ }^{* *} p=0,246$ & ${ }^{* *} p=0,009$ & ${ }^{* *} p=0,058$ \\
\hline \multirow{2}{*}{ İşlem süresi } & ${ }^{*} p=0,199$ & ${ }^{*} p=0,520$ & ${ }^{*} p=0,285$ & ${ }^{*} p=0,589$ \\
\hline & $r=-0,129$ & $r=-0,065$ & $r=-0,108$ & $r=0,055$ \\
\hline \multirow{2}{*}{ İ̆ne kalınlığı } & ${ }^{*} p=0,703$ & ${ }^{*} p=0,635$ & ${ }^{*} p=0,113$ & ${ }^{*} p=0,670$ \\
\hline & $r=-0,039$ & $r=-0,048$ & $r=0,159$ & $r=-0,043$ \\
\hline
\end{tabular}

* Pearson Korelasyon

** Mann Whitney U

*** Kruskall Wallis

$\mathrm{P}<0,05$ istatistiksel olarak anlamlılık değeri olarak kabul edilmiştir.

\section{Tartışma}

Bu çalışmada girişimsel radyoloji bölümünde lokal anestezi ile işlem yapılan hastaların ağrı ve anksiyete durumları değerlendirilmiştir. Çalışmanın sonuçlarına göre işlem yapılan hastalar hafif seviyeden ciddi seviyeye kadar ağrı ve anksiyete deneyimi yaşamaktadırlar. Yapılan birçok çalışmada lokal anestezi ile işlem yapılan hastaların değişen seviyelerde ağrı ve anksiyete deneyimlediği görülmektedir $(10,11,12)$. Girişimsel radyoloji bölümünde çalışan hemşirelerin hastalar işleme alınmadan önce ön değerlendirme kapsamında hastaların ağrı ve anksiyete durumlarını değerlendirmeleri ve hemşirelik girişimlerini bu doğrultuda planlamaları hasta çıktılarına olumlu yansıyacaktır. Çünkü lokal 
anestezi yapılmasına rağmen hastalar hafif seviyeden ciddi seviyeye kadar ağrı deneyimi yaşamaktadırlar. Bu hastaların işlem öncesinde ağrı beklentilerinin ve anksiyete durumlarının belirlenmesi ve uygun girişimlerin (farmakolojik ve nonfarmakolojik yöntemler) belirlenerek uygulanması işlem boyunca hastaların uyumunu artırabilir ve hemodinamik ölçümlerinde ciddi boyutlarda değişimlerin oluşmasını engelleyebilir.

Çalışmamızda hastaların BKl'si ile işlem öncesi anksiyete puanları arasında pozitif yönde zayıf korelasyon bulunmuştur. Bu sonuç; Oyekcin ve arkadaşlarının endokrinoloji bölümüne başvuran psikiyatrik tanı almayan obez hastalarda depresyon ve anksiyete belirtilerinin dağılımını inceledikleri çalışmalarında hastaların orta derecede anksiyete ve depresyon yaşadıkları sonucuyla uyumlu görünmektedir (13).

Çalışmamızda kadın hastalar erkek hastalardan daha yüksek ağrı ve anksiyete puanları ifade etmişlerdir. Gonzales ve arkadaşlarının çalışmalarında da girişimsel radyoloji bölümünde işlem yapılan kadınların daha yüksek anksiyete yaşadıkları ifade edilmiştir (9). Yine aynı şekilde Barrett'in ağız içi bukkal mukoza biyopsisi yapılan hastaları değerlendirdiği çalışmasında kadın hastaların işlem öncesinde erkeklerden daha yüksek derecede anksiyete yaşadıkları sonucuna ulaşılmıştır $(p<0,001)(7)$. Çalışmaların sonuçlarına göre kadın hastalar erkek hastalara göre çok daha fazla anksiyete yaşamakta ve bu duruma bağlı olarak ağrı beklentilerinin de yüksek olduğu görülmektedir. Kadın ve erkek aynı stresöre maruz kalsa bile işlemle ilgili olarak yükledikleri anlamlar ve etkileri farklı olabileceğinden farklı düzeyde anksiyete yaşayabilirler. Kişinin stresöre yüklediği anlam cinsiyet rollerinden de etkilenebilir.

Girişimsel radyoloji bölümünde daha önce benzer işlemler geçiren deneyimli hastaların işlem öncesi ve işlem sonrası anksiyete puanları deneyimi olmayan hastalara göre daha düşük bulunmuştur. Mueller ve arkadaşlarının çalışmalarında da deneyimli hastaların işlem öncesi anksiyete ve ağrı beklentileri ile işlem sonrası ifade ettikleri ağrı puanları deneyimi olmayan hastalarla karşılaştırıldığında daha düşük bulunmuştur (8). Kuivalainen ve arkadaşlarının kemik iliği aspirasyonu yapılan hastaların ağrı ve anksiyetelerini değerlendirdikleri çalışmalarında ise; daha önce ağrılı tıbbi işlem deneyimi yaşayan hastaların daha fazla anksiyete ve lokal anestezi sırasında çok daha fazla ağrı yaşadıklarını ifade etmişlerdir (5). Deneyimli olmak hastaların bazı durumlarda farkındalıklarını artırarak daha az anksiyete ve daha düşük ağrı beklentisinde olmalarını sağlarken, olumsuz ağrı deneyimi yaşayan hastalar için daha fazla anksiyete ve ağrı yaşama kaynağı olabilir. İnvaziv işlemle ilgili bir önceki deneyimin olumlu ya da olumsuz yaşanması daha sonraki süreci etkilemektedir.

Çalışmamızda girişimsel radyoloji bölümünde nonvasküler işlem yapılan hastaların anksiyete ve ağrı puanları vasküler işlem yapılan hastalara göre daha yüksek bulunması, Mueller ve arkadaşlarının çalışmalarında kemik ve göğüs biyopsisi olan hastaların diğer hastalardan daha fazla ağrı deneyimledikleri sonucu ile paralel görünmektedir (8). Özellikle nonvasküler işlemlerin yapıldığı hastalarda işlem sonrasındaki anksiyete puanlarının yüksek oluş sebebi patoloji sonucu ile ilgili belirsizlik olabilir. Çünkü vasküler işlemlerde eş zamanlı olarak saptanan problemler bilinci açık olan hastalara sağlık profesyonelleri tarafından açıklanabilirken patolojik inceleme gerektiren işlemlerin sonuçları ile ilgili olarak bir açıklama yapılamamaktadır. Hastaların anlayabilecekleri şekilde bilgilendirilmeleri, hastalara karşı tutarlı davranılması, hastaların duygularını ifade etmesi için cesaretlendirilmesi ve sağlık ekibi tarafından desteklenmesi önemlidir.

Çalışmamızda hastaların işlem öncesi ve sonrasında ifade ettikleri ağrı ve anksiyete puanları arasında pozitif yönde korelasyon bulunması yapılan diğer çalışmalarda bulunan sonuçlarla benzerdir $(5,7)$. İşlem öncesi hastaların işlemden ağrı beklentilerinin ve anksiyete seviyelerinin sağlık profesyonelleri tarafından değerlendirilmesi, özellikle anksiyete nedenlerinin sorgulanarak sebebe yönelik açıklamaların yapılması, ciddi düzeyde anksiyete yaşayan hastalar için farmakolojik ve nonfarmakoloik girişimlerin uygulanması hastaların işlem sırasında uyumunu artırabilir ve işlem sonrası deneyimlediği ağrı şiddetini azaltabilir. Dolaylı olarak analjezik gereksinimi azalırken analjeziklere bağlı yan etki görülme olasılığı da azalabilir.

Araştırmanın yapıldığı ortamla ilgili problemler nedeniyle örneklem büyüklüğünün yüz hasta ile bitirilmesi araştırmanın sınırlıığıdır. 


\section{Sonuç}

Girişimsel radyoloji bölümünde hastalar hafif seviyeden ciddi seviyeye kadar ağrı ve anksiyete yaşamaktadırlar. Hastaların girişimsel radyoloji bölümüne kabulü ile başlayan süreçte, özellikle lokal anestezi ile işlem yapılan hastaların hemşireler tarafından değerlendirmeleri yapılırken ağrı ve anksiyete durumlarının da değerlendirilmesi önemlidir. Ağrı ve anksiteye yaşayan hastalara ekip yaklaşımı ile uygun farmakolojik ve nonfarmakolojik yöntemlerin belirlenmesi ve uygulanması, hastaların işlem sırasında uyumunu artıracak, hemodinamik belirteçlerin normalden sapmasını en aza indirecek, istenmeyen durumların ortaya çıkışını azaltacak ve hasta memnuniyetini artıracaktır.

Açıklama: Yazarlar arasında çıkar çatışması beyan edilmemiştir. Araştırmanın yürütülmesinde herhangi bir finansal destek alınmamıştır.

\section{Kaynaklar}

1. Tsetisa D, Krokidis M, Negru D, Prassopoulos P. Malignant biliary obstruction: the current role of interventional radiology. Annals of Gastroenterology 2016; 29 (1): 33-6.

2. Itri JN. Patient-centered raiology. Radiographics 2015; 35 (6): 1835-46.

3. Blomberg F, Brulin C, Andertun R, Rydh A. Patients' perception of quality of care in a radiology department: A medical-physical approach. Radiol Nurs 2010; 29 (1): 10-7.

4. Fang AS, Movva L, Ahmed S, Waldman D, Xue J. Clinical efficacy, safety, and feasibility of using video glasses during interventional radiologic porcedures: A Randomized Trial. J Vasc Interv Radiol 2016; 27 (2): $260-7$.

5. Kuivalainen AM, Pitkaniemi J, Widenius T, Elonenc E, Rosenberga P. Anxiety and pain during bone marrow aspiration and biopsy. Scandinavian Journal of Pain 2012; 3 (2): 92-6.

6. Liden Y, Olofsson N, Landgren O, Johansson E. Pain and anxiety during bone marrow aspiration/biopsy: Comparison of ratings among patients versus health-care professionals. European Journal of Oncology Nursing 2012; 16 (3): 323-9.

7. Barrett CS. Anxiety and pain experience of patients undergoing intra-oral buccal mucosa biopsy. Oral Surgery 2009; 2 (3): 111-5.

8. Mueller PR, Biswal S, Halpern EF, Kaufman JA, Lee MJ. Interventional radiologic procedures: Patient anxiety, perception of pain, understanding of procedure, and satisfaction with medication-A prospective study. Radiology $2000 ; 215$ (3): 684-8.

9. Gonzales M, Rutledge DN. Pain and anxiety during less invasive interventional radiology procedures. J Radiol Nurs 2015; 34: 88-93.

10. Tanasale B, Kits J, Kluin PM, Trip A, Kluin-Nelemans HC. Pain and anxiety during bone marrow biopsy. Pain Manag Nurs 2013; 14 (4): 310-7.

11. Kulkarnı S, Johnson PCD, Kettles S, Kasthurı RS. Music during interventional radiological procedures, effect on sedation, pain and anxiety: A randomised controlled trial. Br J Radiol 2012; 85 (1016): 1059-63.

12. Humphrey KL, Lee JM, Donelan K, Kong CY, Williams O, Itauma O, et al. Percutaneous breast biopsy: Effect on short-term quality of life. Radiology $2014 ; 270$ (2) :362-8.

13. Oyekcin DG, Yıldız D, Sahin EM, Gur S. Depression and anxiety in obese. Patients Turk Jem 2011; 15 : $121-4$. 